\title{
A Glutamine Insertion at Codon 432 of RpoB Confers Rifampicin Resistance in Mycobacterium tuberculosis
}

\begin{abstract}
Li-Yin Lai', Li-Yu Hsu', Shang-Hui Weng', Shuo-En Chung ${ }^{1}$, Hui-En Ke ${ }^{1}$, Tzu-Lung Lin', Pei-Fang Hsieh ${ }^{1}$, Wei-Ting Lee ${ }^{2,3}$, Hsing-Yuan Tsai2,3, Wan-Hsuan Lin ${ }^{2,3}$, Ruwen Jou ${ }^{2,3}$ and Jin-Town Wang ${ }^{1,4 *}$

'Department of Microbiology, National Taiwan University College of Medicine, Taipei, Taiwan, ${ }^{2}$ Tuberculosis Research Center, Centers for Disease Control, Ministry of Health and Welfare of Taiwan, Taipei, Taiwan, ${ }^{3}$ Center for Diagnostics and Vaccine Development, Centers for Disease Control, Ministry of Health and Welfare of Taiwan, Taipei, Taiwan, ${ }^{4}$ Department of Internal Medicine, National Taiwan University Hospital, Taipei, Taiwan
\end{abstract}

OPEN ACCESS

Edited by:

Maria Rosalia Pasca

University of Pavia, Italy

Reviewed by:

Divakar Sharma,

Indian Institute of Technology Delhi,

India

Yu Pang,

Beijing Chest Hospital, Capital

Medical University, China

*Correspondence:

Jin-Town Wang

wangjt@ntu.edu.tw

Specialty section:

This article was submitted to

Antimicrobials, Resistance

and Chemotherapy,

a section of the journa

Frontiers in Microbiology

Received: 14 July 2020

Accepted: 23 September 2020

Published: 19 October 2020

Citation:

Lai L-Y, Hsu L-Y, Weng S-H,

Chung $S-E, K e H-E$, Lin $T-L$,

Hsieh P-F, Lee W-T, Tsai H-Y,

Lin W-H, Jou R and Wang J-T (2020)

A Glutamine Insertion at Codon 432

of RpoB Confers Rifampicin

Resistance in Mycobacterium

tuberculosis.

Front. Microbiol. 11:583194.

doi: 10.3389/fmicb.2020.583194
Tuberculosis (TB) is an infectious respiratory disease caused by Mycobacterium tuberculosis and one of the top 10 causes of death worldwide. Treating TB is challenging; successful treatment requires a long course of multiple antibiotics. Rifampicin (RIF) is a first-line drug for treating TB, and the development of RIF-resistant M. tuberculosis makes treatment even more difficult. To determine the mechanism of RIF resistance in these strains, we searched for novel mutations by sequencing. Four isolates, CDC-1, CDC-2, CDC-3, and CDC-4, had high-level RIF resistance and unique mutations encoding RpoB $G^{158} R$, RpoB $V^{168} A$, RpoB $S^{188} P$, and $R p o B ~ Q{ }^{432}$ ins $Q$, respectively. To evaluate their correlation with RIF resistance, plasmids carrying rpo $B$ genes encoding these mutant proteins were transfected into the $\mathrm{H}_{37} \mathrm{Rv}$ reference strain. The plasmid complementation of RpoB indicated that $G^{158} R, V{ }^{168} A$, and $S^{188} P$ did not affect the MIC of RIF. However, the MIC of RIF was increased in $\mathrm{H}_{37} \mathrm{RV}$ carrying RpoB $Q^{432}$ ins $Q$. To confirm the correlation between $R I F$ resistance and $Q^{432}$ ins $Q$, we cloned an rpoB fragment carrying the insertion (encoding $R p o B Q^{432}$ ins $Q$ ) into $\mathrm{H}_{37} \mathrm{Rv}$ by homologous recombination using a suicide vector. All replacement mutants expressing RpoB Q ${ }^{432}$ ins $Q$ were resistant to $R I F(M I C>1 \mathrm{mg} / L$ ). These results indicate that $R p o B$ $Q^{432}$ ins $Q$ causes RIF resistance in $M$. tuberculosis.

Keywords: Mycobacterium tuberculosis, drug resistance, rifampicin, rpoB, codon 432 of RpoB

\section{INTRODUCTION}

Mycobacterium tuberculosis is an important human pathogen that causes tuberculosis (TB). It was first isolated by Robert Koch in 1882, and numerous TB drugs have been developed since the 1930s, although the first effective anti-TB drug was not discovered until 1944 (Vilcheze and Jacobs, 2014; Islam et al., 2017; Long et al., 2019; Mabhula and Singh, 2019). TB is a common, chronic infectious respiratory disease that affects nearly one-third of the world's population (Long et al., 2019; Yong et al., 2019) and is transmitted via aerosol (e.g., cough) from infected persons. According to the World Health Organization, TB is one of the top 10 causes of death worldwide. In 2018, there 
were approximately 10 million people with $\mathrm{TB}$ and 1.4 million deaths due to TB worldwide (World Health Organization [WHO], 2019). Approximately 500,000 new cases were found to be resistant to the most effective first-line drug, rifampicin (RIF), of which $78 \%$ had multidrug-resistant TB (resistant to at least isoniazid and RIF) (World Health Organization [WHO], 2019). According to the Taiwan Centers for Disease Control, there were 9,179 new cases of TB in Taiwan in 2018, and 294 of these were RIF-resistant. Over the period of long-term antiTB therapy, M. tuberculosis is exposed to the appropriate drug concentration, which might lead to the development of drugresistant TB and increase the risk of transmission (Yong et al., 2019). It takes at least 6 months to successfully treat TB, and the development of drug resistance makes therapy even more difficult and is a threat to public health. The treatment of drugresistant $\mathrm{TB}$ requires the administration of more than five drugs for more than 9 months (Vekemans et al., 2020). In addition, RIF-resistant TB is frequently not adequately treated because of a delay in the diagnosis of drug resistance. Such delayed treatment not only has a poor therapeutic effect on the infected patient but also increases the risk of transmission (Boyd et al., 2017; Yong et al., 2019). First-line RIF acts by binding the $\beta$-subunit of RNA polymerase, blocking RNA synthesis, and inducing hydroxyl radical formation, which likely contributes to its killing effect (Piccaro et al., 2014; Lohrasbi et al., 2018). It has been reported that drug resistance develops when mutations in $r p o B$ block RIF binding to the $\beta$-subunit. Most point mutations causing RIF resistance occur in an 81-nucleotide region (codons 426-452 in M. tuberculosis or codons 507-533 in the Escherichia coli codon numbering system) of $r p o B$ that is called the RIF resistancedetermining region (RRDR) (Pang et al., 2013; Chikaonda et al., 2017). According to previous studies, $>90 \%$ of RIF-resistant TB strains have mutations in the RRDR within codon 435, 445, and 450 (codon 516, 526, and 531 in E. coli) (Pang et al., 2013; Swain et al., 2020). Drug resistance is a major challenge for TB control. Due to the slow growth rate of $M$. tuberculosis, conventional drug susceptibility testing takes several weeks. Therefore, sequencing drug resistance-related mutations can be used to quickly detect drug-resistant TB, significantly reducing the duration of therapy, and avoiding treatment delays. Thus, we examined the effects of novel mutations in known target gene regions and mutations outside of the target region on RIF resistance in $M$. tuberculosis with the aim to expand upon known RIF resistance-causing mutations for use in clinical molecular diagnostics.

\section{MATERIALS AND METHODS}

\section{Bacteria Strains}

Clinical isolates were obtained from the Reference Laboratory of Mycobacteriology of the Taiwan Centers for Disease Control. M. tuberculosis $\mathrm{H}_{37} \mathrm{Rv}$ was used as the reference strain. $M$. tuberculosis $\mathrm{H}_{37} \mathrm{Rv}$ and clinical isolates were cultured in Difco ${ }^{\text {TM }}$ Middlebrook $7 \mathrm{H} 9$ medium (BD REF: 271310; MD, NJ, United States) supplemented with $10 \%$ oleic acid/albumin/dextrose/catalase (OADC), 0.5\% glycerol, and $0.05 \%$ tween -80 at $37^{\circ} \mathrm{C}$ (Tan et al., 2006). E. coli DH10B was grown in Luria broth (LBL405.1; BioShop, Burlington, Canada). All experiments involving $M$. tuberculosis strains were conducted at the Biosafety level 3 lab in the National Taiwan University College of Medicine and followed institutional biosafety procedures.

\section{Isolation of Clinical Strains and Drug Susceptibility Testing}

Clinical isolates of $M$. tuberculosis were tested in the Reference Laboratory of Mycobacteriology of the Taiwan Centers for Disease Control. Each isolate was initially obtained from a patient and was inoculated in solid and liquid culture. The minimum inhibitory concentration (MIC) of RIF was determined using a Sensititre ${ }^{\mathrm{TM}}$ Mycobacterium tuberculosis MIC Plate (MYCOTB; Thermo Fisher Scientific, Cleveland, $\mathrm{OH}$, United States) according to the manufacturer's instructions. The bacterial culture was adjusted to a $0.5 \mathrm{McFarland}$ standard and then added to the Sensititre ${ }^{\mathrm{TM}}$ plate, which was covered with an adhesive plastic seal. After incubation at $37^{\circ} \mathrm{C}$, the results were recorded with a Sensititre ${ }^{\mathrm{TM}}$ Vizion $^{\mathrm{TM}}$ Digital MIC Viewing System. The critical concentration of RIF was $1 \mathrm{mg} / \mathrm{L}$.

\section{Microplate Alamar Blue Assays (MABAs)}

Microplate alamar blue assays were performed as previously described with minor modifications (Burke et al., 2017). Briefly, M. tuberculosis strains were cultured in Middlebrook 7H9 medium, and then the $\mathrm{OD}_{600 \mathrm{~nm}}$ was adjusted to 0.1. A 200$\mu \mathrm{L}$ aliquot of each prepared bacterial suspension was placed in a 96-well sterile plate (LabServ, Singapore) and incubated at $37^{\circ} \mathrm{C}$ for 14 days with and without RIF $(0.03-512 \mathrm{mg} / \mathrm{L})$. After 14 days of incubation, $50 \mu \mathrm{L}$ of a freshly prepared 1:1 mixture of Alamar blue (alamarBlue ${ }^{\circledR}$; BioRad, Hercules, CA, United States) and $10 \%$ tween 80 was added to each well. Then, the plate was incubated at $37^{\circ} \mathrm{C}$ for $48 \mathrm{~h}$, and the color was recorded. Blue indicates no growth, and pink indicates growth. During incubation and staining, the plate was sealed with an adhesive plate seal.

\section{RpoB Expression Plasmids}

The plasmid pMN437 was used to express RpoB in M. tuberculosis (Steinhauer et al., 2010). Derivative plasmids

TABLE 1 | Rifampicin (RIF) resistance levels of clinical strains as measured by Sensititre $^{\text {TM }}$ Mycobacterium tuberculosis MIC Plate.

\begin{tabular}{llcc}
\hline Strains & RpoB substitutions & RpoB Codon change & $\begin{array}{c}\text { MIC of RIF } \\
\text { (mg/L) }\end{array}$ \\
\hline CDC-1 & $\mathrm{G}^{158} \mathrm{R} \& \mathrm{~V}^{170} \mathrm{~F}$ & $158 \mathrm{GGC} \rightarrow \mathrm{CGC}$ & 8 \\
& & $170 \mathrm{GTC} \rightarrow \pi \mathrm{TC}$ & $>16$ \\
$\mathrm{CDC}-2$ & $\mathrm{~V}^{168} \mathrm{~A} \& \mathrm{~V}^{170} \mathrm{~F}$ & $168 \mathrm{GTG} \rightarrow \mathrm{GCG}$ & $>16$ \\
& & $170 \mathrm{GTC} \rightarrow \pi \mathrm{TC}$ & \\
$\mathrm{CDC}-3$ & $\mathrm{~V}^{170} \mathrm{~F} \& \mathrm{~S}^{188} \mathrm{P}$ & $170 \mathrm{GTC} \rightarrow \pi \mathrm{TC}$ & $>16$ \\
& & $188 \mathrm{TCC} \rightarrow \mathrm{CCC}$ & \\
$\mathrm{CDC}-4$ & $\mathrm{~S}^{431} \mathrm{G} \& \mathrm{Q}^{432}$ ins & $431 \mathrm{AGC} \rightarrow \mathrm{GGC}$ & \\
& & $432 \mathrm{CAA} \rightarrow \mathrm{CAACAA}$ & \\
\hline
\end{tabular}

RIF resistance: $>1 \mathrm{mg} / \mathrm{L}$. MIC, minimum inhibitory concentration. 
TABLE 2 | Plasmids used in this study.

\begin{tabular}{|c|c|c|c|c|}
\hline Plasmids & Amino acid substitutions* & Target strain & $\begin{array}{c}\text { Predicted } \\
\text { consequence }\end{array}$ & $\begin{array}{c}\text { Obtained } \\
\text { phenotypic } \\
\text { consequences }\end{array}$ \\
\hline pMN437-RpoB $G^{158} R$ & RpoB $G^{158} R$ & $\mathrm{H}_{37} \mathrm{Rv}$ & $S \rightarrow R$ & $S \rightarrow S$ \\
\hline pMN437-RpoB V ${ }^{168} A$ & RpoB V ${ }^{168} A$ & $\mathrm{H}_{37} \mathrm{Rv}$ & $S \rightarrow R$ & $S \rightarrow S$ \\
\hline pMN437-RpoB $S^{188} \mathrm{P}$ & RpoB $S^{188} P$ & $\mathrm{H}_{37} \mathrm{Rv}$ & $S \rightarrow R$ & $S \rightarrow S$ \\
\hline pMN437-RpoB-CDC-4 & RpoB $S^{431} G \& Q^{432}$ ins $Q$ & $\mathrm{H}_{37} \mathrm{Rv}$ & $\mathrm{S} \rightarrow \mathrm{R}$ & $S \rightarrow R$ \\
\hline pMN437-RpoB Q ${ }^{432}$ insQ & RpoB Q ${ }^{432}$ insQ & $\mathrm{H}_{37} \mathrm{Rv}$ & $S \rightarrow R$ & $S \rightarrow R$ \\
\hline pGOAL19-Rv RpoB Q432insQ & RpoB Q ${ }^{432}$ insQ & $\mathrm{H}_{37} \mathrm{Rv}$ & $\mathrm{S} \rightarrow \mathrm{R}$ & $\mathrm{S} \rightarrow \mathrm{R}$ \\
\hline
\end{tabular}

$S$, sensitive strain; $R$, resistant strain. ${ }^{\star}$ Rifampicin resistance-related amino acid substitutions.

TABLE 3 | Susceptibility test results of clinical isolates and $\mathrm{H}_{37} \mathrm{Rv}$ strains carrying RpoB expression plasmids as measured by microplate Alamar blue assays.

\begin{tabular}{|c|c|c|c|c|}
\hline \multirow[t]{2}{*}{ Strains } & \multirow[t]{2}{*}{ RpoB substitutions } & \multicolumn{3}{|c|}{ MIC of RIF (mg/L) } \\
\hline & & Exp. 1 & Exp. 2 & Exp. 3 \\
\hline $\mathrm{H}_{37} \mathrm{Rv}$ & None & 0.125 & 0.03 & 0.125 \\
\hline $\mathrm{H}_{37} \mathrm{Rv}: \mathrm{pMN} 437$ & None & 0.03 & 0.03 & 0.125 \\
\hline CDC-1 & $V^{170} F \& G^{158} R$ & 32 & 4 & - \\
\hline $\begin{array}{l}\mathrm{H}_{37} \mathrm{Rv}: \mathrm{pMN} 437- \\
\mathrm{RpoB} \\
\mathrm{G}^{158} \mathrm{R}\end{array}$ & $G^{158} R^{\star}$ & 0.06 & 0.125 & - \\
\hline CDC-2 & $V^{170} F \& V^{168} A$ & 256 & 512 & - \\
\hline $\begin{array}{l}\mathrm{H}_{37} \mathrm{Rv}: \mathrm{pMN} 437- \\
\mathrm{RpoB} \\
\mathrm{V}^{168} \mathrm{~A}\end{array}$ & $V^{168} A^{*}$ & 0.125 & 0.25 & - \\
\hline $\begin{array}{l}\mathrm{H}_{37} \mathrm{Rv}: \mathrm{pMN} 437- \\
\mathrm{RpoB} \\
\mathrm{S}^{188} \mathrm{P}\end{array}$ & $S^{188} P^{\star}$ & 0.06 & 0.03 & - \\
\hline CDC-4 & $S^{431} G \& Q^{432} i n s Q$ & 128 & 128 & 256 \\
\hline $\begin{array}{l}\mathrm{H}_{37} \mathrm{Rv}: \mathrm{pMN} 437- \\
\mathrm{RpoB} \\
\mathrm{Q}^{432} \text { insQ }\end{array}$ & $\mathrm{Q}^{432}$ ins $^{*}$ & 128 & 64 & 128 \\
\hline $\begin{array}{l}\mathrm{H}_{37} \mathrm{Rv}: \mathrm{pMN} 437- \\
\text { RpoB-CDC-4 }\end{array}$ & $S^{431} G \& Q^{432} i n s Q^{*}$ & 256 & 128 & 256 \\
\hline
\end{tabular}

Exp., experiment; MIC, minimum inhibitory concentration. *Amino acid substitutions in RpoB based on pMN437. - Was not included in the experiment. RIF resistance: $>1 \mathrm{mg} / \mathrm{L}$.

carrying resistance-associated $r p o B$ mutations were generated using the QuikChange II Site-Directed Mutagenesis Kit (Agilent, Santa Clara, CA, United States). The primers used are shown in Supplementary Table 1. M. tuberculosis was transformed by electroporation at $2,500 \mathrm{~V}, 1,000 \Omega$, and $25 \mu \mathrm{F}$ and recovered in $10 \mathrm{~mL}$ of Middlebrook $7 \mathrm{H} 9$ medium supplemented with $10 \%$ OADC and 0.5\% glycerol for $24 \mathrm{~h}$ (Larsen et al., 2007; Lai et al., 2018). Recovered cells were then plated on $\mathrm{BBL}^{\mathrm{TM}} 7 \mathrm{H} 11$ solid agar (BD REF: 212203; BD, MD, NJ, United States) containing $50 \mathrm{mg} / \mathrm{L}$ hygromycin and incubated at $37^{\circ} \mathrm{C}$ for 4 weeks.

\section{Site-Directed Mutagenesis}

The putative resistance-associated $r p o B$ mutations were amplified by PCR from the genomic DNA of the resistant strains as a template and then cloned into the ScaI site of the suicide plasmid pGOAL19 (Addgene; MA, United States) (Parish and Stoker,
2000). The primers used are shown in Supplementary Table 1. The resulting plasmids were transformed into $M$. tuberculosis $\mathrm{H}_{37} \mathrm{Rv}$, and point mutants were selected after two rounds of homologous recombination, as previously described (Parish and Stoker, 2000; Larsen et al., 2007).

\section{DNA Sequencing}

Mycobacterium tuberculosis isolates were lysed with InstantGet ${ }^{\mathrm{TM}}$ DNA Extraction Solution (Catalog Number: 17001; HNG, Taipei, Taiwan) and heat-killed $\left(100^{\circ} \mathrm{C}\right.$ for $15 \mathrm{~min}$ ). Then, the supernatants of heat-killed M. tuberculosis isolates were added to the PCR reagent containing KOD Xtreme $^{\mathrm{TM}}$ Hot Start DNA Polymerase (Catalog Number: 71976; Novagen, CA, United States) and gene-specific primers, rpoB out F1 and rpoB-out-R (Supplementary Table 1), to amplify the $r p o B$ fragment. The PCR products were sent for sequencing (Mission Biotech, Taipei, Taiwan) and were verified by capillary electrophoresis (ABI 3730xl; Thermo Fisher Scientific, Cleveland, $\mathrm{OH}$, United States). The $r p o B$ sequences of clinical strains CDC-1, CDC-2, and CDC-4 were submitted to NCBI (GenBank accession numbers: MT774526, MT774527, and MT774528, respectively).

\section{RESULTS}

\section{Identification of Novel rpoB Mutations in RIF-Resistant Clinical Isolates}

Four clinical isolates, CDC-1, CDC-2, CDC-3, and CDC-4, had high-level RIF resistance and different novel mutations within the $r p o B$ gene. The RIF resistance levels of clinical strains were determined using a Sensititre ${ }^{\mathrm{TM}}$ Mycobacterium tuberculosis MIC Plate. The MIC of RIF for CDC-1 was $8 \mathrm{mg} / \mathrm{L}$, and the MICs of RIF for CDC-2, CDC-3, and CDC-4 were $>16 \mathrm{mg} / \mathrm{L}$ (Table 1). Sequencing showed that each of these four clinical isolates harbored genes encoding two amino acid changes in RpoB. When compared to the sequence of the reference strain $\mathrm{H}_{37} \mathrm{Rv}$, in CDC-1, the $\mathrm{G}$ at codon 158 was replaced with $\mathrm{R}\left(\mathrm{G}^{158} \mathrm{R}\right)$ and the $\mathrm{V}$ at codon 170 was replaced with $\mathrm{F}\left(\mathrm{V}^{170} \mathrm{~F}\right)$. In CDC2 , the $\mathrm{V}$ at codon 168 was replaced with $\mathrm{A}\left(\mathrm{V}^{168} \mathrm{~A}\right)$ and the $\mathrm{V}$ at codon 170 was replaced with $\mathrm{F}\left(\mathrm{V}^{170} \mathrm{~F}\right)$. In $\mathrm{CDC}-3$, the $\mathrm{V}$ at codon 170 of RpoB was substituted with $F\left(V^{170} F\right)$, and the $S$ at codon 188 was replaced with $\mathrm{P}\left(\mathrm{S}^{188} \mathrm{P}\right)$. In $\mathrm{CDC}-4$, the $\mathrm{S}$ at codon 431 


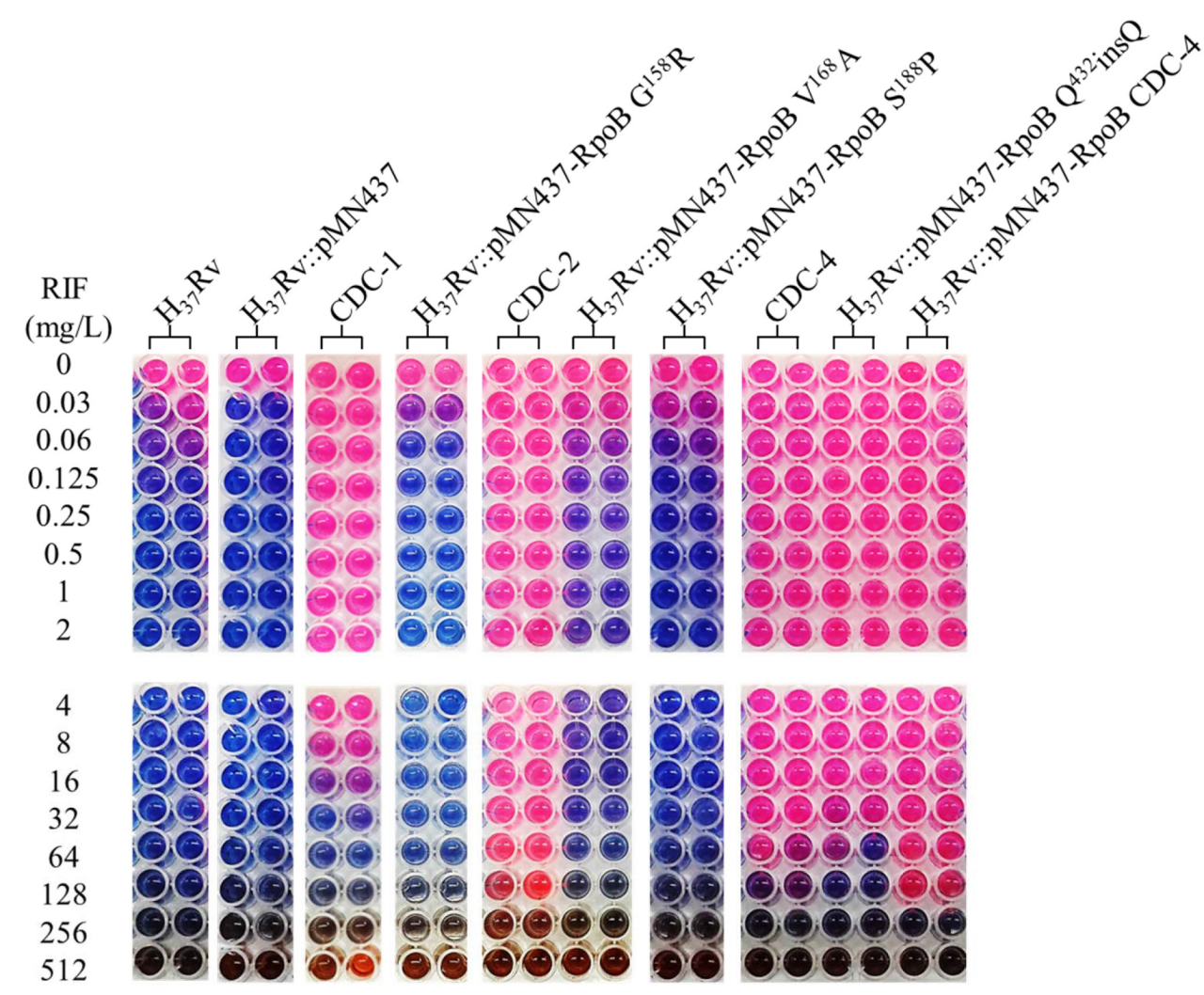

FIGURE 1 | Rifampicin (RIF) susceptibility test for Mycobacterium tuberculosis strains expressing wild-type and mutant RpoB as measured by microplate Alamar blue assays (MABAs). The MIC of RIF for M. tuberculosis strains carrying RpoB expression plasmids was measured by MABA. M. tuberculosis was cultured in 7 H9 broth containing different concentrations of RIF for 2 weeks and then stained with Alamar blue for 2 days. CDC-1, CDC-2, and CDC-4 are RIF-resistant clinical strains that harbored RpoB amino acid changes $\left(\mathrm{G}^{158} \mathrm{R} \& \mathrm{~V}^{170} \mathrm{~F}, \mathrm{~V}^{168} \mathrm{~A} \& \mathrm{~V}^{170} \mathrm{~F}\right.$, and $\mathrm{S}^{431} \mathrm{G} \& \mathrm{Q}^{432}$ ins $\mathrm{Q}$, respectively). Red indicates bacterial growth, and blue indicates no growth. The critical concentration for RIF resistance was $1.0 \mathrm{mg} / \mathrm{L}$. All experiments were performed in duplicate to confirm reproducibility and repeated at least twice with similar results (Table 3).

was replaced with $G\left(S^{431} G\right)$ and a $Q$ was inserted at codon 432 $\left(\mathrm{Q}^{432}\right.$ ins $\left.\mathrm{Q}\right)$. However, $\mathrm{G}^{158} \mathrm{R}, \mathrm{V}^{168} \mathrm{~A}, \mathrm{~S}^{188} \mathrm{P}$, and $\mathrm{Q}^{432}$ ins $\mathrm{Q}$ had not previously been confirmed to be related to drug resistance.

\section{An RpoB Q ${ }^{432}$ ins $Q$ Expression Plasmid Increases the MIC of RIF in $\mathbf{H}_{37} \mathbf{R v}$}

Clinical isolates CDC-1, CDC-2, CDC-3, and CDC-4 had highlevel RIF resistance and harbored unique RpoB amino acid changes $\left(\mathrm{G}^{158} \mathrm{R}, \mathrm{V}^{168} \mathrm{~A}, \mathrm{~S}^{188} \mathrm{P}\right.$, and $\mathrm{Q}^{432}$ ins $\mathrm{Q}$, respectively). To evaluate the association between these unique amino acid changes and the RIF resistance of the clinical isolates, plasmids (pMN437-derived) expressing these RpoB proteins were transformed into $\mathrm{H}_{37} \mathrm{Rv}$ (Table 2), and RIF susceptibility was measured in these strains by a MABA. The results showed that the MICs of RIF for the wild-type strains, $\mathrm{H}_{37} \mathrm{Rv}$ and $\mathrm{H}_{37} \mathrm{Rv}$ :pMN437, were 0.03-0.125 $\mathrm{mg} / \mathrm{L}$. The MIC of RIF for clinical strain CDC-1 was $4-32 \mathrm{mg} / \mathrm{L}$, that for clinical strain CDC-2 was 256-512 mg/L, and that for clinical strain CDC-4 was $128-256 \mathrm{mg} / \mathrm{L}$. These results were consistent with the MIC data obtained with the Sensititre ${ }^{\mathrm{TM}}$ Mycobacterium tuberculosis MIC Plate. However, the MIC of RIF for clinical strain CDC3 could not be determined by the MABA because it could not be cultured. The MIC of RIF for $\mathrm{H}_{37} \mathrm{Rv}$ :pMN437-RpoB $\mathrm{G}^{158} \mathrm{R}$, $\mathrm{H}_{37} \mathrm{Rv}$ :pMN437-RpoB V ${ }^{168} \mathrm{~A}$, and $\mathrm{H}_{37} \mathrm{Rv}$ :pMN437-RpoB $\mathrm{S}^{188} \mathrm{P}$ was $0.03-0.25 \mathrm{mg} / \mathrm{L}$, that for $\mathrm{H}_{37} \mathrm{Rv}$ :pMN437-CDC-4 was $128-$ $256 \mathrm{mg} / \mathrm{L}$, and that for $\mathrm{H}_{37} \mathrm{Rv}$ :pMN437-RpoB $\mathrm{Q}^{432}$ insQ was 64-128 mg/L (Tables 2, 3, Figure 1). These results showed that $\mathrm{H}_{37} \mathrm{Rv}$ :pMN437-RpoB $\mathrm{G}^{158} \mathrm{R}, \mathrm{H}_{37} \mathrm{Rv}$ :pMN437-RpoB $\mathrm{V}^{168} \mathrm{~A}$, and $\mathrm{H}_{37} \mathrm{Rv}$ :pMN437-RpoB $\mathrm{S}^{188} \mathrm{P}$ were not resistant to RIF (MIC $<1 \mathrm{mg} / \mathrm{L}$ ). The MIC of RIF for $\mathrm{H}_{37} \mathrm{Rv}$ :pMN437-CDC-4 was the same as that of clinical strain CDC-4, and the MIC of RIF for $\mathrm{H}_{37} \mathrm{Rv}$ :pMN437-RpoB $\mathrm{Q}^{432}$ insQ was two-fold lower than that for $\mathrm{H}_{37} \mathrm{Rv}$ :pMN437-CDC-4 and clinical strain CDC-4. This suggests that RpoB $\mathrm{G}^{158} \mathrm{R}, \mathrm{RpoB} \mathrm{V}^{168} \mathrm{~A}$, and $\mathrm{RpoB} \mathrm{S}^{188} \mathrm{P}$ likely do not contribute to RIF resistance, whereas RpoB $Q^{432}$ insQ contributes to high-level RIF resistance in M. tuberculosis.

\section{RpoB $\mathbf{Q}^{432}$ ins $Q$ Confers RIF Resistance to $M$. tuberculosis $\mathrm{H}_{37} \mathrm{Rv}$}

Among the tested RpoB expression plasmids, only RpoB $\mathrm{Q}^{432}$ ins $\mathrm{Q}$ increased the MIC of RIF in $\mathrm{H}_{37} \mathrm{Rv}$. To further confirm that the RpoB $\mathrm{Q}^{432}$ insQ was correlated with RIF resistance, unmarked mutants of $\mathrm{H}_{37} \mathrm{Rv}$ expressing $\mathrm{RpoB} \mathrm{Q}^{432}$ ins $\mathrm{Q}$ were generated. The $r p o B$ fragment with the CAA insertion was 


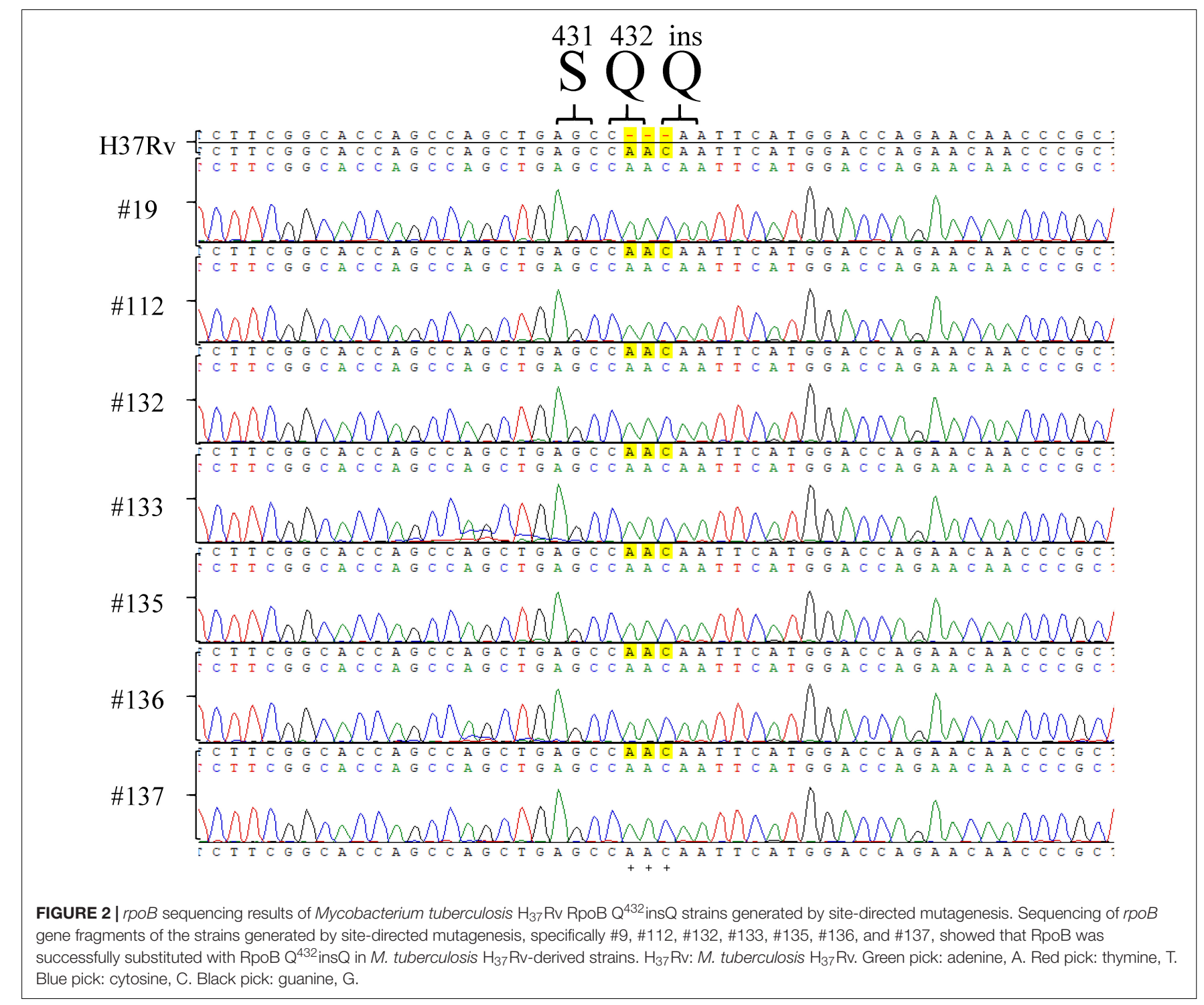

subcloned from pMN437-RpoB $\mathrm{Q}^{432}$ insQ into the ScaI site of the pGOAL19 plasmid, and the resulting construct, pGOAL19Rv RpoB $Q^{432}$ insQ (Table 2) was checked by sequencing. Then, the plasmid was transformed into M. tuberculosis $\mathrm{H}_{37} \mathrm{Rv}$, and the unmarked replacement mutant (RpoB $\mathrm{Q}^{432}$ insQ) was selected after two rounds of homologous recombination. DNA sequencing confirmed that seven strains (\#19, \#112, \#132, \#133, $\# 135$, \#136, and \#137) had the CAA insertion in codon 432 of $r p o B$, which leads to a $\mathrm{Q}$ insertion (Figure 2). All tested strains were resistant to RIF, with an MIC $>1 \mathrm{mg} / \mathrm{L}$.

\section{DISCUSSION}

Clinical strains CDC-1, CDC-2, and CDC-3 have high-level RIF resistance and unique $r p o B$ gene mutations. All of them also encoded $\mathrm{V}^{170} \mathrm{~F}$, which is a well-known RIF-resistance associated mutation, as it has been reported that M. tuberculosis isolates encoding the $\mathrm{V}^{170} \mathrm{~F}$ mutation have high-level resistance to RIF (8-32 mg/L) (Heep et al., 2000). According to our data, $\mathrm{G}^{158} \mathrm{R}, \mathrm{V}^{168} \mathrm{~A}$, and $\mathrm{S}^{188} \mathrm{P}$ mutations likely did not contribute to RIF resistance in these strains. However, strain CDC-2 had a RIF MIC of 256-512 mg/L, which was 32-64 fold higher than the MIC previously reported for a strain encoding RpoB V ${ }^{170} \mathrm{~F}$ (Heep et al., 2000), suggesting that strain CDC2 might have another drug-resistance mechanism not involving RpoB. Because we only sequenced the $r p o B$ genes of RIFresistant strains, resistance mechanisms outside $r p o B$ could not be detected. Mutations causing other antibiotic resistance could be missed too. Chromosome mutations comprise the major mechanism causing drug resistance in M. tuberculosis (Miotto et al., 2018). Drug resistance in strains could be caused by other resistance mechanisms such as antibiotic modifications or neutralization, augmented efflux pumps, porin alterations, and the downregulation of cell-wall permeability (Mnyambwa et al., 2017; Sharma et al., 2018). 
Codons 431 and 432 of $r p o B$ are located in the RRDR (Friehs, 2004), and mutations in this region are related to RIF resistance (Sandgren et al., 2009). Mutations at codon $431\left(S^{431} \mathrm{~T}, \mathrm{~S}^{431} \mathrm{I}, \mathrm{S}^{431} \mathrm{R}\right.$, and $\left.\mathrm{S}^{431} \mathrm{G}\right)$ were previously reported to be associated with RIF resistance (Kapur et al., 1994; Sajduda et al., 2004; Chan et al., 2007). Multiple mutations including codon 431 or 432 of $\mathrm{RpoB}$ resulted in higherlevel RIF resistance (MIC > $100 \mathrm{mg} / \mathrm{L}$ ) (Bahrmand et al., 2009). We also demonstrated that plasmid complementation or chromosomal mutagenesis of $\mathrm{Q}^{432}$ ins $\mathrm{Q}$ alone could cause RIF resistance, whereas $S^{431} \mathrm{G}$ plus $\mathrm{Q}^{432}$ ins $\mathrm{Q}$ complementation resulted in a two-fold higher MIC of RIF (Tables 2, 3, Figure 1).

RIF interacts with the $\beta$-subunit of RpoB, and most RIF resistance in $M$. tuberculosis is caused by mutations in the RRDR of RpoB (Tupin et al., 2010). The domain structure of $\mathrm{RpoB}$ was previously deduced by analyzing the crystal structure, which showed that RpoB directly interacts with RIF via 12 hydrogen bonds (Nusrath Unissa et al., 2016). Molecular docking experiments showed stronger RIF binding by wild-type RpoB than by mutant RpoB proteins (Nusrath Unissa et al., 2016). Q432 is an energetically favorable binding site and is considered part of the active site that is involved in ligand binding (Campbell et al., 2001; Nusrath Unissa et al., 2016). RpoB Q ${ }^{432}$ insQ might influence the binding enthalpy to weaken the molecular interaction between RpoB and RIF, which could result in RIF resistance.

We observed that CDC-4 grew slower compared to the $\mathrm{H}_{37} \mathrm{Rv}$ strain. Therefore, mutants survived better only in the presence of RIF. Multiple mutations in $r p o B$ have been reported, shown to result in increased drug resistance (Bahrmand et al., 2009). The occurrence of multiple mutations could be accumulated due to continuous RIF usage after a first mutation or they could occur simultaneously in high RIF environments.

Rifampicin is an effective drug used to treat most cases of drug-susceptible TB (Long et al., 2019). However, cases of RIF resistance have been reported since the early 1990s, leading to problems in TB control (Zaw et al., 2018). In M. tuberculosis, drug resistance is mostly caused by genetic changes rather than gene transfer from other bacteria (Tupin et al., 2010; Zaw et al., 2018). Thus, sequencing wellknown mutation sites is important to detect drug-resistant M. tuberculosis. Several molecular diagnostic methods have been developed for the rapid detection of drug resistance in M. tuberculosis (Yong et al., 2019). Nevertheless, more comprehensive information on drug resistance-associated mutations must be established to improve the diagnosis and treatment of TB.

\section{REFERENCES}

Bahrmand, A. R., Titov, L. P., Tasbiti, A. H., Yari, S., and Graviss, E. A. (2009). High-level rifampin resistance correlates with multiple mutations in the rpoB gene of pulmonary tuberculosis isolates from the Afghanistan border of Iran. J. Clin. Microbiol. 47, 2744-2750. doi: 10.1128/jcm.r00 548-09

\section{CONCLUSION}

In summary, we studied four isolates with high-level RIF resistance and unique mutations encoding $R p o B G^{158} R$, RpoB $\mathrm{V}^{168} \mathrm{~A}, \mathrm{RpoB} \mathrm{S}^{188} \mathrm{P}$, and $\mathrm{RpoB} \mathrm{Q}^{432}$ insQ. Results of plasmid complementation of RpoB indicated that $G^{158} R, V^{168} A$, and $\mathrm{S}^{188} \mathrm{P}$ of $\mathrm{RpoB}$ do not affect the MIC of RIF. However, the transfer of pMN437-RpoB $\mathrm{Q}^{432}$ insQ plasmids to $M$. tuberculosis $\mathrm{H}_{37} \mathrm{Rv}$ or chromosomal mutagenesis generating RpoB $\mathrm{Q}^{432}$ ins $\mathrm{Q}$ turned sensitive strains into RIF-resistant strains. Therefore, RpoB $\mathrm{Q}^{432}$ insQ confers RIF resistance in M. tuberculosis.

\section{DATA AVAILABILITY STATEMENT}

The datasets presented in this study can be found in online repositories. The names of the repository/repositories and accession number(s) can be found in the article/Supplementary Material.

\section{AUTHOR CONTRIBUTIONS}

J-TW designed the study. L-YL, P-FH, T-LL, and J-TW discussed the results and revised the manuscript. W-TL, H-YT, W-HL, and RJ provided and analyzed the clinical strains. L-YL, S-HW, S-EC, L-YH, and H-EK prepared materials and performed experiments. L-YL and P-FH analyzed the data. L-YL wrote the manuscript. All authors reviewed and approved the final version of the manuscript.

\section{ACKNOWLEDGMENTS}

This study was supported by the Ministry of Science and Technology, the Excellent Translational Medicine Research Projects of National Taiwan University College of Medicine and National Taiwan University Hospital, the Liver Disease Prevention and Treatment Research Foundation of Taiwan, and "Center of Precision Medicine" from the Featured Areas Research Center Program within the framework of the Higher Education Sprout Project by the Ministry of Education (MOE) in Taiwan.

\section{SUPPLEMENTARY MATERIAL}

The Supplementary Material for this article can be found online at: https://www.frontiersin.org/articles/10.3389/fmicb. 2020.583194/full\#supplementary-material

Boyd, R., Ford, N., Padgen, P., and Cox, H. (2017). Time to treatment for rifampicin-resistant tuberculosis: systematic review and meta-analysis. Int. J. Tuberc. Lung Dis. 21, 1173-1180. doi: 10.5588/ijtld.17.0230

Burke, R. M., Coronel, J., and Moore, D. (2017). Minimum inhibitory concentration distributions for first- and second-line antimicrobials against Mycobacterium tuberculosis. J. Med. Microbiol. 66, 1023-1026. doi: 10.1099/ jmm.0.000534 
Campbell, E. A., Korzheva, N., Mustaev, A., Murakami, K., Nair, S., Goldfarb, A., et al. (2001). Structural mechanism for rifampicin inhibition of bacterial rna polymerase. Cell 104, 901-912. doi: 10.1016/s0092-8674(01)00286-0

Chan, R. C., Hui, M., Chan, E. W., Au, T. K., Chin, M. L., Yip, C. K., et al. (2007). Genetic and phenotypic characterization of drug-resistant Mycobacterium tuberculosis isolates in Hong Kong. J. Antimicrob. Chemother. 59, 866-873. doi: $10.1093 / \mathrm{jac} / \mathrm{dkm} 054$

Chikaonda, T., Ketseoglou, I., Nguluwe, N., Krysiak, R., Thengolose, I., Nyakwawa, F., et al. (2017). Molecular characterisation of rifampicin-resistant Mycobacterium tuberculosis strains from Malawi. Afr. J. Lab. Med. 6:463.

Friehs, K. (2004). Plasmid copy number and plasmid stability. Adv. Biochem. Eng. Biotechnol. 86, 47-82.

Heep, M., Rieger, U., Beck, D., and Lehn, N. (2000). Mutations in the beginning of the rpoB gene can induce resistance to rifamycins in both Helicobacter pylori and Mycobacterium tuberculosis. Antimicrob. Agents Chemother. 44, 1075-1077. doi: 10.1128/aac.44.4.1075-1077.2000

Islam, M. M., Hameed, H. M. A., Mugweru, J., Chhotaray, C., Wang, C., Tan, Y., et al. (2017). Drug resistance mechanisms and novel drug targets for tuberculosis therapy. J. Genet. Genom. 44, 21-37. doi: 10.1016/j.jgg.2016. 10.002

Kapur, V., Li, L. L., Iordanescu, S., Hamrick, M. R., Wanger, A., Kreiswirth, B. N., et al. (1994). Characterization by automated DNA sequencing of mutations in the gene (rpoB) encoding the RNA polymerase beta subunit in rifampin-resistant Mycobacterium tuberculosis strains from New York City and Texas. J. Clin. Microbiol. 32, 1095-1098. doi: 10.1128/jcm.32.4.1095-1098. 1994

Lai, L. Y., Lin, T. L., Chen, Y. Y., Hsieh, P. F., and Wang, J. T. (2018). Role of the Mycobacterium marinum ESX-1 secretion system in sliding motility and biofilm formation. Front. Microbiol. 9:1160. doi: 10.3389/fmicb.2018.01160

Larsen, M. H., Biermann, K., Tandberg, S., Hsu, T., and Jacobs, W. R. Jr. (2007). Genetic manipulation of Mycobacterium tuberculosis. Curr. Protoc. Microbiol. Chap. 10:Unit 10A 12.

Lohrasbi, V., Talebi, M., Bialvaei, A. Z., Fattorini, L., Drancourt, M., Heidary, M., et al. (2018). Trends in the discovery of new drugs for Mycobacterium tuberculosis therapy with a glance at resistance. Tuberculosis 109, 17-27. doi: 10.1016/j.tube.2017.12.002

Long, B., Liang, S. Y., Koyfman, A., and Gottlieb, M. (2019). Tuberculosis: a focused review for the emergency medicine clinician. Am. J. Emerg. Med. 38, 1014-1022. doi: 10.1016/j.ajem.2019.12.040

Mabhula, A., and Singh, V. (2019). Drug-resistance in Mycobacterium tuberculosis: where we stand. Med. Chem. Commun. 10, 1342-1360. doi: 10.1039/ c9md00057g

Miotto, P., Zhang, Y., Cirillo, D. M., and Yam, W. C. (2018). Drug resistance mechanisms and drug susceptibility testing for tuberculosis. Respirology 23, 1098-1113. doi: $10.1111 /$ resp.13393

Mnyambwa, N. P., Kim, D. J., Ngadaya, E. S., Kazwala, R., Petrucka, P., and Mfinanga, S. G. (2017). Clinical implication of novel drug resistance-conferring mutations in resistant tuberculosis. Eur. J. Clin. Microbiol. Infect. Dis. 36, 2021-2028. doi: 10.1007/s10096-017-3027-3

Nusrath Unissa, A., Hassan, S., Indira Kumari, V., Revathy, R., and Hanna, L. E. (2016). Insights into RpoB clinical mutants in mediating rifampicin resistance in Mycobacterium tuberculosis. J. Mol. Graph. Model. 67, 20-32. doi: 10.1016/j. jmgm.2016.04.005

Pang, Y., Lu, J., Wang, Y., Song, Y., Wang, S., and Zhao, Y. (2013). Study of the rifampin monoresistance mechanism in Mycobacterium tuberculosis. Antimicrob. Agents Chemother. 57, 893-900. doi: 10.1128/aac.01024-12

Parish, T., and Stoker, N. G. (2000). Use of a flexible cassette method to generate a double unmarked Mycobacterium tuberculosis tlyA plcABC mutant by gene replacement. Microbiology 146(Pt 8), 1969-1975. doi: 10.1099/00221287-1468-1969
Piccaro, G., Pietraforte, D., Giannoni, F., Mustazzolu, A., and Fattorini, L. (2014). Rifampin induces hydroxyl radical formation in Mycobacterium tuberculosis. Antimicrob. Agents Chemother. 58, 7527-7533. doi: 10.1128/aac.03169-14

Sajduda, A., Brzostek, A., Poplawska, M., Augustynowicz-Kopec, E., Zwolska, Z., Niemann, S., et al. (2004). Molecular characterization of rifampin- and isoniazid-resistant Mycobacterium tuberculosis strains isolated in Poland. J. Clin. Microbiol. 42, 2425-2431. doi: 10.1128/jcm.42.6.2425-2431.2004

Sandgren, A., Strong, M., Muthukrishnan, P., Weiner, B. K., Church, G. M., and Murray, M. B. (2009). Tuberculosis drug resistance mutation database. PLoS Med. 6:e1000002. doi: 10.1371/journal.pmed.1000002

Sharma, D., Bisht, D., and Khan, A. U. (2018). Potential alternative strategy against drug resistant tuberculosis: a proteomics prospect. Proteomes 6:26. doi: 10.3390/ proteomes6020026

Steinhauer, K., Eschenbacher, I., Radischat, N., Detsch, C., Niederweis, M., and Goroncy-Bermes, P. (2010). Rapid evaluation of the mycobactericidal efficacy of disinfectants in the quantitative carrier test EN 14563 by using fluorescent Mycobacterium terrae. Appl. Environ. Microbiol. 76, 546-554. doi: 10.1128/aem. 01660-09

Swain, S. S., Sharma, D., Hussain, T., and Pati, S. (2020). Molecular mechanisms of underlying genetic factors and associated mutations for drug resistance in Mycobacterium tuberculosis. Emerg. Microb. Infect. 9, 1651-1663. doi: 10.1080/ 22221751.2020.1785334

Tan, T., Lee, W. L., Alexander, D. C., Grinstein, S., and Liu, J. (2006). The ESAT6/CFP-10 secretion system of Mycobacterium marinum modulates phagosome maturation. Cell Microbiol. 8, 1417-1429. doi: 10.1111/j.1462-5822.2006.00721. $\mathrm{x}$

Tupin, A., Gualtieri, M., Roquet-Baneres, F., Morichaud, Z., Brodolin, K., and Leonetti, J. P. (2010). Resistance to rifampicin: at the crossroads between ecological, genomic and medical concerns. Int. J. Antimicrob. Agents 35, 519523. doi: 10.1016/j.ijantimicag.2009.12.017

Vekemans, J., Brennan, M. J., Hatherill, M., Schrager, L., Fritzell, B., Rutkowski, K., et al. (2020). Preferred product characteristics for therapeutic vaccines to improve tuberculosis treatment outcomes: key considerations from World Health Organization consultations. Vaccine 38, 135-142. doi: 10.1016/j.vaccine. 2019.10.072

Vilcheze, C., and Jacobs, W. R. Jr. (2014). Resistance to isoniazid and ethionamide in Mycobacterium tuberculosis: genes, mutations, and causalities. Microbiol. Spectr. 2:MGM2-0014-2013. doi: 10.1128/microbiolspec.MGM2-0014-2013

World Health Organization [WHO] (2019). Global Tuberculosis Report 2019. Geneva: World Health Organization.

Yong, Y. K., Tan, H. Y., Saeidi, A., Wong, W. F., Vignesh, R., Velu, V., et al. (2019). Immune biomarkers for diagnosis and treatment monitoring of tuberculosis: current developments and future prospects. Front. Microbiol. 10:2789. doi: 10. 3389/fmicb.2018.02789

Zaw, M. T., Emran, N. A., and Lin, Z. (2018). Mutations inside rifampicinresistance determining region of rpoB gene associated with rifampicinresistance in Mycobacterium tuberculosis. J. Infect. Public Health 11, 605-610. doi: 10.1016/j.jiph.2018.04.005

Conflict of Interest: The authors declare that the research was conducted in the absence of any commercial or financial relationships that could be construed as a potential conflict of interest.

Copyright (C) 2020 Lai, Hsu, Weng, Chung, Ke, Lin, Hsieh, Lee, Tsai, Lin, Jou and Wang. This is an open-access article distributed under the terms of the Creative Commons Attribution License (CC BY). The use, distribution or reproduction in other forums is permitted, provided the original author(s) and the copyright owner(s) are credited and that the original publication in this journal is cited, in accordance with accepted academic practice. No use, distribution or reproduction is permitted which does not comply with these terms. 